Greenwood, Dr Sheila Gore, Dr Gwyneth Jones, Dr Linda McCallum, Mrs Marian McGill, Dr Gillian Raab, Sister Fiona Raeside, Mr Peter Ronald, Ms Alison Rowlands, Ms Rebecca Temperley, Dr Edwin Van Teijlingen, Dr Eric Walker, Sister Jenny Whelans, Mr Jim Whitelaw, Ms Lynn Williamson, and Ms Gill Young.

1 Bird AG, Gore SM, Jolliffe DW, Burns SM. Anonymous HIV surveillance in Saughton prison, Edinburgh. AIDS 1992;6:725-33.

2 Bird AG, Gore SM, Jolliffe DW, Burns SM. Second anonymous HIV surveillance and in Saughton prison, Edinburgh: prisoners give a lead to other heterosexuals on being HIV tested. AIDS (in press).

3 Gore SM, Basson J, Bird AG, Goldberg DJ. Uptake of confidential, named HIV testing in Scottish prisons. Lancet 1992;340:907-8.

4 Gore SM, Jolliffe DW, Bird AG. Prisoners' uptake of confidential named HIV testing. Lancet 1992;339:1491-2.

5 Johnson AM, Wadsworth J, Wellings $K$, Bradshaw S, Field J. Sexual lifestyles and HIV risk. Nature 1992;360:410-2.

6 ACSF Investigators. AIDS and sexual behaviour in France. Nature 1992;360: 407-9.

(Accepted 17 May 1993)

\title{
Lifelong exercise and stroke
}

\author{
Roger Shinton, Gian Sagar
}

\begin{abstract}
Objectives-To examine the potential of lifelong patterns of increased physical activity to prevent stroke.

Design-Case-control study.

Setting-11 general practices in west Birmingham.

Subjects-125 men and women who had just had their first stroke and were aged 35-74 and 198 controls frequency matched for age and sex recruited over 24 months during 1988-90. Exclusion criteria were a previous history of stroke, mitral valvular heart disease combined with atrial fibrillation, primary or metastatic cerebral neoplasm, or coagulation disorder or myeloproliferative disease.

Main outcome measures-Odds ratios for stroke related to lifetime history of exercise after 15 years of age.
\end{abstract}

Results-A history of vigorous exercise during the ages 15-25 appeared to protect from stroke: odds ratio adjusted for age and sex 0.33 (95\% confidence interval 0.2 to 0.6 ). This effect was independent of other potential risk factors. Increasing years of participation in vigorous exercise between the ages of 15 and 55 produced an increasing protection from stroke $(p<0.001)$. In the 65 cases and 169 controls who were free of cardiac ischaemia, peripheral vascular disease, and poor health recent vigorous exercise and walking were protective against stroke: odds ratios of $0.41 \quad(0.2$ to 1.0$)$ for recent vigorous exercise and $0.30(0.1$ to 0.7 ) for recent walking.

Conclusions-Appreciable protection from stroke in later life is conferred by vigorous exercise in early adulthood. This increased level of physical activity should, if possible, be continued lifelong.

University of Birmingham, Department of Medicine, Dudley Road Hospital, Birmingham B18 7QH Roger Shinton, Wellcome Trust fellow in clinical epidemiology

Department of Radiology, Dudley Road Hospital Gian Sagar, consultant radiologist

Correspondence to: Dr Shinton, University of Birmingham, Department of Geriatric Medicine, The Hayward Building, Selly Oak Hospital, Birmingham B29 6JD.

$B M 9$ 1993;307:231-4

\section{Introduction}

Evidence is growing that exercise can protect against stroke, ${ }^{1}$ but increased levels of physical activity are not yet widely recognised protective factors for stroke. ${ }^{2-4}$ There is, however, a more general acceptance that exercise reduces risks of coronary heart disease and hypertension. ${ }^{47}$ The importance of exercise in early adult life in protection from stroke has received little attention. This is somewhat surprising because a history of recent exercise is closely related to overall general health. Thus the relation between stroke and recent exercise can be confounded by illnesses which limit exercise and predispose to cerebrovascular events. This confounding should be minimal when exercise in early adulthood is examined.

In one cohort study examining the importance of exercise in youth participation in university sports was associated with a later reduction in the risk of fatal stroke. $^{8}$ This, however, was not confirmed in the college alumni with non-fatal strokes. ${ }^{9}$ The influence of potential confounding variables was not examined in these analyses.

The west Birmingham stroke project, a community based case-control study, was designed to examine risk factors for stroke in people's lifestyles, including lifelong patterns of exercise.

\section{Subjects and methods}

The detailed methods of the case-control study have been described previously. ${ }^{10}$ People registered with 11 general practices in west Birmingham comprised the study population of 101000 .

\section{SUBJECTS}

Between 1 October 1989 and 30 September 1990 we recruited men and women who had just had their first stroke and were aged 35-74. To ensure maximum recruitment each general practice was phoned weekly, and the admission records of Dudley Road Hospital were regularly checked for patients with entries suggestive of stroke. The patients were assessed by one of us (RS) using the standard criteria of the World Health Organisation: rapidly developing clinical signs of focal and, at times, global (applied to patients in deep coma or with subarachnoid haemorrhage) loss of cerebral function with symptoms lasting more than 24 hours or leading to death and with no apparent cause other than that of vascular origin. ${ }^{11}$ Both hospital and community based patients with stroke were, if fit, offered computed tomography of the head (without contrast). The scans were reported by one of us (GS). Cerebral infarction was diagnosed if a head scan or autopsy was performed within 21 days of the start of a stroke and there was either no evidence of haemorrhage or a pattern of predominant infarction.

Patients were excluded from the study if they had a prior history of stroke (but not transient ischaemic attack), a history of mitral valvular heart disease combined with atrial fibrillation, a history of primary or metastatic cerebral neoplasm, or a history of coagulation disorder or myeloproliferative disease. Patients who died before assessment could be made and those who refused to participate were also excluded.

Control subjects were randomly selected from the general practice population to broadly match the distribution of age and sex among the patients with stroke (frequency matching). All those on the registers of the 11 participating practices aged $35-74$ were eligible for inclusion. The same exclusions applied as for the patients with stroke. The controls were each sent a letter signed by their general practitioner, which was followed up by a telephone call or visit to arrange an appointment for assessment, usually at their practice surgery. 
ASSESSMENT

The subjects were all anthropometrically assessed and interviewed by one observer (RS) with a standard structured questionnaire. The patients with stroke were seen as soon as possible after the event. When disability prevented an adequate response the closest relative or friend was interviewed. The subjects were divided by their responses to the questionnaire into those who did or did not engage in regular vigorous exercise during youth (aged 15-25), early middle age (25-40), and late middle age (40-55). Vigorous activity in the month before the stroke (cases) or interview (controls) was assessed in the same way. Examples of vigorous exercise provided by the questionnaire were digging, running, swimming, cycling, playing tennis or squash, and keeping fit. Whether subjects had recently been walkers was determined by the question: "Have you walked one mile outdoors in the past month?"

By means of standard methods, ${ }^{12}$ Harpenden skinfold callipers were used to measure subscapular skinfold thickness (mean of two records), and a portable stadiometer was used to measure height when possible. Peak body mass index (weight $(\mathrm{kg}) /($ height $(\mathrm{m}))^{2}$ ) was estimated from standing or derived standing height (adjusted lying height) and recall of lifelong maximum weight. ${ }^{10}$ Sex specific interquartile ranges among the controls were established for both measures of body fat.

The subjects were grouped into four 10 year age groups for analysis. Their sex, race (black, white, Asian, or other), cigarette smoking (never, former, or current), and weekly alcohol consumption (none, light (11-14 units), moderate (15-29 units), or heavy ( $>29$ units)) were recorded. They were asked about their main occupation (and husband's occupation for married women), and this was used to determine social class. Their intake of saturated fats was derived from their responses to three simple questions about food frequency to give four categories of intake. Their perceived health status was recorded (good, average, or poor), and a history of hypertension, peripheral vascular disease, or diabetes was recorded if they could recall a doctor having diagnosed the illness. A history of cardiac ischaemia was recorded if they could recall a doctor having diagnosed either angina or a heart attack, and a family history of stroke was recorded

for age and sex) according tolength of time when regular vigorous exercise undertaken. (Bars indicate $95 \%$ confidence intervals) if a first degree relative was reported to have had a stroke.

\section{STATISTICAL ANALYSIS}

A computer software program (EGRET) ${ }^{13}$ was used to calculate odds ratios (relative risk) and their $95 \%$ confidence intervals according to the methods described by Breslow and Day. ${ }^{14}$ Mantel-Haentzel methods were used to provide an estimate of the odds ratio after adjustment for one or two other variables. Adjustment for several variables was made by use of a multiple logistic regression model. Regression models were fitted using exposure levels of a given risk factor as discrete (factored) variables.

\section{Results}

Over the 24 months of recruitment 125 patients with stroke were eligible for inclusion (12 patients who had had their first stroke at the appropriate time were excluded), of whom 43 were managed at home. No patient (or relative) declined to participate. Cerebral infarction was confirmed in 81 patients, intracerebral haemorrhage in five, subarachnoid haemorrhage in four, and the subtype was unknown in 35 . Assessment was within seven days of the start of the stroke for 85 patients and within 14 days for 112 patients. Of the 220 controls selected and contacted, 13 were excluded and 198 of the remainder agreed to participate. It was originally estimated that recruitment would yield about 150 cases and 150 controls. The median ages of the patients with stroke and the controls were 66 and 63 respectively.

The subject's answers to questions about cardiovascular risk factors were compared with records available in general practice and hospital notes. With previous medical records on diabetes, cardiac ischaemia, and peripheral vascular disease as the standard, the questionnaire had overall sensitivities of $84 \%$ among the patients with stroke and $83 \%$ among the controls. Specificities were $92 \%$ and $99 \%$ respectively. A history of cigarette smoking was recalled by $72(96 \%)$ of the 75 patients with a stroke who had any record of cigarette smoking and by $79(98 \%)$ of the 81 controls who had any record of smoking.

All the subjects or their relatives were able to give a history of exercise. Exercise during the age categories 25-40 and 40-55 was not assessed for subjects aged under 40 and 55 respectively. Table I shows the relative risk of stroke according to age when vigorous exercise was undertaken. The odds ratio for stroke was most reduced among those reporting vigorous exercise in youth, and this was not appreciably affected by adjustment (unadjusted odds ratio of 0.41 ) for the following possible confounding variables: race, social class, peak body mass index, subscapular skinfold thickness, cigarette smoking, alcohol consumption, dietary intake of saturated fat, family history of stroke, and histories of hypertension, diabetes mellitus, and cardiac ischaemia. The adjusted values all fell within the range $0 \cdot 30-0 \cdot 45$. In particular, an adjustment for perceived health status did not attenuate the apparent effect (odds ratio of 0.38 ), which would have been expected if it was due to a tendency to negativity among patients with stroke. Adjustment for recent vigorous exercise and recent walking had minimal effects (odds ratios of 0.45 and 0.41 respectively).

Among the 105 cases and 161 controls aged over 54 an increasing protection from stroke was seen as the duration of exercise in earlier years increased (figure). This trend was highly significant $(p<0.001)$.

Because of concern that a bias had been introduced by relatives of patients with stroke being less able to recall activity in youth, an analysis was performed which was restricted to the 95 cases and 196 controls

\begin{tabular}{llllr}
$35-54$ & 1.0 & $9: 11$ & $0.20(0.1$ to 0.8$)$ & $5: 26$ \\
$55-64$ & 1.0 & $17: 22$ & $0.34(0.1$ to 1.0$)$ & $19: 47$ \\
$65-74$ & 1.0 & $44: 35$ & $0.36(0.2$ to 0.8$)$ & $31: 57$ \\
Cigarette smokingt: & & & \\
Never & 1.0 & $14: 36$ & $0.65(0.2$ to 2.0$)$ & $8: 33$ \\
Former & 1.0 & $28: 14$ & $0.19(0.1$ to 0.5$)$ & $26: 55$ \\
Current & 1.0 & $28: 18$ & $0.30(0.1$ to 0.8$)$ & $21: 42$ \\
\hline
\end{tabular}

Odds ratios adjusted for: *age; †sex; łage and sex. 
who could respond for themselves. The odds ratio, adjusted for age and sex, remained the same $(0.33(0.2$ to $0 \cdot 6)$ ).

Table II shows the protective effect of vigorous exercise in youth examined separately by sex, age, and smoking. A similar benefit was seen in all groups.

When the 81 patients with proved cerebral infarction were analysed separately vigorous exercise in youth was protective in both sexes: odds ratios adjusted for age of $0.29(0.1$ to 0.7$)$ for men and 0.35 $(0.1$ to 1.0$)$ for women and an odds ratio adjusted for age and sex of $0.31(0.2$ to 0.6$)$ for men and women.

Subjects with a history of myocardial ischaemia, peripheral vascular disease, and poor health were excluded from analysis of recent exercise, leaving 65 cases and 169 controls. Odds ratios adjusted for age and sex indicated that a protective effect was conferred by recent walking $(0.3(0.1$ to 0.7$))$ and recent vigorous exercise $(0.41(0 \cdot 2$ to $1 \cdot 0))$. Multiple risk factor adjustment (including recent walking and vigorous exercise, exercise when aged 15-25, age group, sex, cigarette smoking, and peak body mass index in the logistic model) did not appreciably affect the protective effects of recent walking (odds ratio $0.32(0.1$ to 0.7$)$ ), recent exercise $(0.61(0.2$ to 1.5$))$, and exercise when aged $15-25(0 \cdot 20(0 \cdot 1$ to $0 \cdot 4))$.

\section{Discussion}

The results of this study suggest that vigorous exercise undertaken in early adulthood confers substantial protection against stroke. Recent vigorous exercise and regular walking were also apparently protective. These effects were seen in both sexes and all age groups.

The principal potential source of error in this study was the possibility that results could have been due to recall bias: patients with stroke or their relatives, but not controls, forgetting activities undertaken in earlier years. There are several reasons why this seems an unlikely explanation for the results. Firstly, the patients with stroke seemed able to recall with increased frequency other factors such as cardiac ischaemia, diabetes, and former cigarette smoking. ${ }^{15}$ Assessment of questionnaire validity did not suggest impaired recall among the patients with stroke compared with the controls. In addition, long term recall of vigorous exercise has been reported to be reliable elsewhere. ${ }^{16}$ Secondly, adjustment for perceived general health did not attenuate the relation as might have been expected if a generally negative response among the patients with stroke was the explanation for the associations. Thirdly, exclusion of surrogate responders from the analysis did not alter the results. Finally, the strength and consistency of the observed association would require a very considerable recall bias to explain it. The potential problems of selection biases for cases and controls should have been minimal as all the subjects came from the same community. The decision on inclusion was made before risk factors were assessed. There was almost no room for bias in the rates of response to have influenced the results.

Confounding variables seemed to offer no explanation for the observed associations. None of the potential confounding variables examined reduced the relation to any degree. Although adjustment for social class had little effect on the results, it is possible that the findings might be due in part to different social classes tending to leave school at different ages. Those in higher social classes who stayed at school are likely to have continued to participate in organised vigorous activities. Conversely, educationally based sporting activity during youth may partly explain why higher social class is associated with a decreased risk of stroke.

\section{Public health implications}

- Despite increasing evidence that physical activity can protect against stroke, little attention has been paid to the protective effects of exercise throughout adulthood

- Vigorous exercise in early adulthood provides substantial protection against stroke in both sexes, and lifelong continuation of exercise gives maximum protection

- Recent vigorous exercise and regular walking are also apparently protective

The results would have been strengthened if the data could have been collected by an observer blinded to each subject's status (case or control). Blinding, however, would have produced major logistical problems in a study including patients with acute stroke in hospital and controls in the community, and it was considered to be impractical.

Previous studies have not examined the possible independent benefits of exercise in early adulthood on the risk of stroke. A series of cohorts and casecontrol studies have, however, suggested a benefit from increased levels of activity in middle age and beyond. ${ }^{17-24}$ The importance of exercise habits when young in determining future patterns of activity is now appreciated..$^{25}$ No study suggesting an adverse effect of exercise on the risk of stroke has been identified. The protective effect of prolonged patterns of exercise against stroke is made more plausible by the evidence of the beneficial effects of exercise on the risks of coronary heart disease, hypertension, and diabetes mellitus. ${ }^{672627}$

This study adds weight to the evidence that exercise protects against the risk of stroke. Vigorous exercise in early adult life seems particularly beneficial, and lifelong continuation of exercise offers maximum protection. Vigorous exercise in early adulthood may well have an independent benefit but clearly also encourages lifelong patterns of habitual exercise.

We thank the patients and staff of the 11 participating general practices for their generous cooperation and Dr D G Beevers, Professor M J S Langman, Dr I J Perry, and Professor G A Rose for their advice. The project was funded by the Wellcome Trust.

\section{Appendix}

The staff of the participating general practices were $\mathrm{Dr} O \mathrm{O}$ Dervish, Dr S H Dervish, Dr J M E Hyde, Dr Y Iqbal, Dr H Shire, and Mrs Diane Adams of Bearwood Road Surgery, Smethwick; Dr M E Clarkson, Dr I G Cox, Dr L A Pike, Dr A Thake, and Mrs Olive Woollas of Birchfield Medical Centre; Dr D L Child, Dr A Gaston, Dr M Hale, Dr R A Loveless, Dr D G Towers, Dr J L Wearn, and Mrs Ann Anderson of Cape Hill Medical Centre; Dr M Hall, Dr P A Hamilton, Dr M J O Massey, Dr P M O Massey, and Mrs Lynn Craig of Church Lane Surgery, Handsworth; Dr G Atkins, Dr S K Bhalla, Dr D K Majevadia, Dr B Watson, and Ms Kamla Mack of Hamstead Road Surgery, Handsworth/Great Barr; Dr B Colston, Dr I Fletcher, Dr J A Paris, Dr D R Morgan, and Mrs Catherine Bakewell of Lee Bank Health Centre; Dr E G Carolan, Dr D Haas, Dr P K Misra, Dr S Mukerjee, Dr E O'Brien, Dr R Orsborn, Dr S Ray, Mrs Patricia Lazenby, and Mrs Shiela Lamb of Newtown Health Centre; Dr P H R Bryson, Dr M Forrest, Dr M J Laird, Dr A H Macdonald, Dr L L Ostrowski, Dr R Takes, and Ms Christine Lynch of Plough and Harrow Medical Centre, Ladywood; Dr A J G Campbell, Dr F E Campbell, Dr D H Johnson, Dr J Kay, Dr M J Mortimer, Dr R M Palmer, Dr P Preston, and Mrs Jo Walker of Sherwood House Surgery, Bearwood; Dr S S Bath, Dr D K Calderwood, Dr V S Calderwood, Dr D K Nandi, and Mrs Deborah Bond of Tower Hill Health Centre; and Dr 
A P Joseph, Dr F A Khan, Dr D A Harrington, Dr K E Roberts, Dr P T Y Wong, and Mrs Lynn George of Victoria Health Centre, Smethwick.

\footnotetext{
1 Wannamethee G, Shaper AG. Physical activity and stroke in middle aged British men. BMf 1992;304:597-601.

2 Dyken ML, Wolf PA, Barnett HJM, Bergan J, Hass WK, Kannel WB, et al. Risk factors in stroke: a statement for physicians by the subcommittee on risk factors and stroke of the Stroke Council. Stroke 1984;15:1105-11.

3 Royal College of Physicians Working Party. Stroke-towards better management. London: Royal College of Physicians, 1989.

4 Royal College of Physicians. Medical aspects of exercise. Benefits and risks. London: Royal College of Physicians, 1991.

5 Leon AS, Connett J, Jacobs DR, Rauramaa R. Leisure-time physical activity levels and risk of coronary heart disease and death: the multiple risk factor levels and risk of coronary heart disease and

6 Nelson L, Jennings GL, Elser MD, Korner PI. Effects of changing levels of physical activity on blood pressure and haemodynamics in essential physical activity on blood pressure and haemodynamics in essential

Shaper AG, Wannamethee G. Physical activity and ischaemic heart disease in middle-aged British men. Br Heart f 1991;66:384-94.

8 Paffenbarger RS, Wing AL. Characteristics in youth predisposing to fatal stroke in later years. Lancet 1967;i:753-4.

Paffenbarger RS, Wing AL. Chronic disease in former college students: early precursors of non-fatal stroke. Am f Epidemiol 1971;94:524-30.

10 Shinton R. Sagar G, Beevers G. The relation of alcohol consumption to cardiovascular risk factors and stroke. The west Birmingham stroke project. INeurol Neurosurg Psychiatry 1993;56:458-62.

11 World Health Organisation. Cerebrovascular diseases-prevention, treatment and rehabilitation. Technical repont series no. 469. Geneva: WHO, 1971.

2 Weiner JS, Lourie JA. Human Biology: a guide to field methods. IBP Handbook No. 9. Oxford: Blackwell Scientific Publications, 1969.

3 EGRET. Reference manual. Seattle: Statistics and Epidemiology Research Corporation, 1990.

14 Breslow NE, Day NE. Statistical methods in cancer research. Vol 1. The analysis
}

of case-control studies. Lyon: International Agency for Research on Cancer, 1980.

15 Shinton RA. Lifestyle and the risk of stroke [MD thesis]. Cambridge: University of Cambridge, 1992.

16 Blair SN, Dowda M, Pate RR, Kronenfeld J, Howe HG, Parker G, et al. Reliability of long-term recall of participation in physical activity by middle aged men and women. Am $\mathcal{F}$ Epidemiol 1991;133:266-75.

17 Paffenbarger RS, Brand RJ, Sholtz RI, Jung DL. Energy expenditure, cigarette smoking, and blood pressure level as related to death from specific diseases. Am $\mathcal{F}$ Epidemiol 1978;108:12-8.

18 Kannel WB, Sorlie P. Some health benefits of physical activity. Arch Intern Med 1979;139:857-61.

19 Salonen JT, Puska P, Tuomilehto J. Physical activity and risk of myocardial infarction, cerebral stroke and death. Am f Epidemiol 1982;115:526-37.

20 Herman B, Schmitz PIM, Leyten ACM, Van Luijk JH, Frenken CWGM, Op de Coul AAW, et al. Multivariate logistic analysis of risk factors for stroke in Tilburg, The Netherlands. Am $\mathcal{F}$ Epidemiol 1983;118:514-25.

21 Paffenbarger RS, Hyde RT, Wing AL, Steinmetz CH. A natural history of athleticism and cardiovascular health. ҰAMA 1984;252:491-5.

22 Lapidus L, Bengtsson C. Socioeconomic factors and physical activity in relation to cardiovascular disease and death. A 12 year follow up of participants in a population study of women in Gothenberg, Sweden. $B$ Heart f 1986;55:295-301.

23 Paganini-Hill A, Ross RK, Henderson BE. Postmenopausal oestrogen treatment and stroke: a prospective study. BMF 1988;297:519-22.

24 Folsom AR, Prineas RJ, Kaye SA, Munger RG. Incidence of hypertension and stroke in relation to body fat distribution and other risk factors in older women. Stroke 1990;21:701-6.

25 Young and unfit? [editorial]. Lancet 1992;340:19-20.

26 Helmrich SP, Ragland DR, Leung RW, Paffenbarger RS. Physical activity and reduced occurrence of non-insulin-dependent diabetes mellitus. $N$ Engl fMed 1991;325:147-52.

27 Manson JE, Rimm EB, Stampfer MJ, Colditz GA, Willett WC, Krolewsk AS, et al. Physical activity and incidence of non-insulin-dependent diabetes mellitus in women. Lancet 1991;338:774-8.

(Accepted 21 May 1993)

\title{
Psychological distress in pregnancy and preterm delivery
}

\author{
Morten Hedegaard, Tine Brink Henriksen, Svend Sabroe, Niels Jørgen Secher
}

Abstract

Objective-To investigate if psychological distress during pregnancy is associated with increased risk of preterm delivery.

Design-Prospective, population based, follow up study with repeated measures of psychological distress (general health questionnaire), based on the use of questionnaires.

Setting-Antenatal care clinic and delivery ward, Aarhus University Hospital, Denmark.

Subjects -8719 women with singleton pregnancies attending antenatal care for the initial visit between 1 August 1989 and 30 September 1991; 5872 women $(67 \%)$ completed all questionnaires.

Main outcome measure-Preterm delivery. Estimation of gestational age at delivery was mainly based on early ultrasound measurements.

Results-In 197 cases (3.6\%) the woman delivered prematurely (less than 259 days). A dose-response relation between psychological distress in the 30th week of pregnancy and risk of preterm delivery was found, but distress measured in the 16th week was not related to preterm delivery. Control of confounding was secured by the use of multivariate logistic regression models. Relative risk for preterm delivery was $1.22(95 \%$ confidence interval 0.84 to $1 \cdot 79)$ for moderate distress and $1.75(1.20$ to 2.54$)$ for high distress in comparison to low distress.

Conclusions-Psychological distress later in pregnancy is associated with an increased risk of preterm delivery. Future interventional studies should focus on ways of lowering psychological distress in late pregnancy.

\section{Introduction}

Low birth weight, which is the result of preterm delivery or fetal growth retardation, is an important determinant of the newborn's health. ${ }^{1}$ Preterm delivery, defined as delivery before 259 days' gestation, ${ }^{2}$ is the obstetric complication with the largest impact on perinatal mortality, ${ }^{3}$ and is a major determinant of neonatal morbidity, ${ }^{4}$ and neurological and neurobehavioural sequelae. ${ }^{5}$

Advances in neonatal intensive care have improved the chances of survival of the preterm infant, ${ }^{6}$ but the rate of preterm delivery remains unchanged. Problems associated with preterm delivery will not be solved by therapeutic interventions alone, and emphasis has been placed on the role of prevention.

The aetiology of preterm delivery is largely unknown, but a few causes have been identified: mother's education and socioeconomic status, smoking, low weight and height before pregnancy, young age. Stress has been hypothesised as a risk factor for preterm delivery, ${ }^{8}$ perhaps by inducing release of oxytocin. ${ }^{9}$

The aim of this prospective cohort study was to evalute the association between psychological distress and preterm delivery, and if such an association was present to test the existence of a dose-response relation. Other determinants of preterm delivey were adjusted for in the analysis by using multivariate statistical models.

\section{Methods}

From 1 August 1989 to 30 September 1991, a cohort of pregnant women was established at the Department of Obstetrics at Arhus University Hospital. Women living in a well defined geographical area with a population of about 250000 are referred to the department, which is the only maternity unit in the city. A few women with specific pregnancy complications, such as diabetes or isoimmunisation, are referred to the department from a larger geographical area.

Danish speaking women attending the antenatal programme for the initial examination were eligible for inclusion in the study. In Denmark more than $97 \%$ of all pregnant women attend an antenatal programme. After exclusion of women with twin

Dr Hedegaard. 